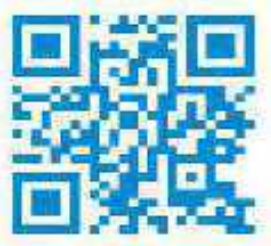

\title{
Cardiovascular Risk Factors and Cardiovascular Risk in People Living with HIV: Comparison of Four Cardiovascular Risk Prediction Algorithms
}

\author{
Abdou Razak Moukaila, Edem Komi Mossi, Nouroudine Amadou, Komi Dzidzonu Nemi, Mouhaman- \\ Inouwa Kpelafia, Yawovi Mawufemo Tsevi, Lidaw Déassoua Bawe, Agbeko Kodjo Djagadou, Majeste Ihou \\ Wateba, \& Awalou Mohaman Djibril \\ University of Lome
}

\section{ABSTRACT}

Introduction: The objective of our study was to evaluate, in a population of Togolese People Living With HIV (PLWHIV), the agreement between three scores derived from the general population namely the Framingham score, the Systematic Coronary Risk Evaluation (SCORE), the evaluation of the cardiovascular risk (CVR) according to the World Health Organization (WHO) and the CVR evaluation equation derived from the Data collection on Adverse effects of anti-HIV Drugs (D.A.D).

Methods: We conducted a descriptive and analytical cross-sectional study including 212 HIV-infected patients recruited from the day hospital of the Infectious Diseases Department of the Sylvanus Olympio University Hospital. The level of agreement between the different scores was estimated using the Pearson correlation test and the Cohen Kappa coefficient.

Keywords: cardiovascular risk, HIV, framingham, D.A.D, score, togo.

Classification: FOR CODE: WG 120

Language: English 



\title{
Cardiovascular Risk Factors and Cardiovascular Risk in People Living with HIV: Comparison of Four Cardiovascular Risk Prediction Algorithms
}

\author{
Abdou Razak Moukaila ${ }^{\alpha^{*}}$, Edem Komi Mossi ${ }^{\sigma}$, Nouroudine Amadou $^{\rho}, K_{\text {Komi Dzidzonu Nemi }}{ }^{{ }^{\circ}}$ \\ Mouhaman-Inouwa Kpelafia ${ }^{\ddagger}$, Yawovi Mawufemo Tsevi ${ }^{\S}$, Lidaw Déassoua Bawe ${ }^{\varepsilon}$, Agbeko \\ Kodjo Djagadou ${ }^{x}$, Majeste Ihou Wateba $^{\theta}, \&$ Awalou Mohaman Djibril' ${ }^{\zeta}$
}

\begin{abstract}
Introduction: The objective of our study was to evaluate, in a population of Togolese People Living With HIV (PLWHIV), the agreement between three scores derived from the general population namely the Framingham score, the Systematic Coronary Risk Evaluation (SCORE), the evaluation of the cardiovascular risk (CVR) according to the World Health Organization (WHO) and the CVR evaluation equation derived from the Data collection on Adverse effects of anti-HIV Drugs (D.A.D).
\end{abstract}

Methods: We conducted a descriptive and analytical cross-sectional study including 212 $H I V$-infected patients recruited from the day hospital of the Infectious Diseases Department of the Sylvanus Olympio University Hospital. The level of agreement between the different scores was estimated using the Pearson correlation test and the Cohen Kappa coefficient.

Results: The median age of the participants (68.9\% female) was 50.2 years (IQR: 44.8-56.o). Eighty-seven point seven percent of the participants were on highly active antiretroviral therapy, $87.1 \%$ of whom were on a combination of two nucleoside inhibitors and one nonnucleoside inhibitor. The most represented cardiovascular risk factors were abdominal obesity (56.1\%), HDL hypocholesterolemia (52.4\%) and hypertension (44.8\%). The median cardiovascular risk was 6.3\% (IQR: 3.9-11.2), o.o\% (IQR: $0.0-1.0$ ), $4.0 \%$ (IQR: $3.0-8.0$ ), $3.0 \%$ (IQR: 1.95-5.01), based on the Framingham, SCORE, WHO and D.A.D scores respectively. There was a strong positive and statistically significant correlation between CVR scores based on the general population and scores obtained using the D.A.D algorithm: Framingham and D.A.D ( $r=0.80 ; p$ o.OO1); SCORE and D.A.D ( $r$ $=0.58 ; p$ o.OO1); WHO and D.A.D ( $r=0.65$; $p^{\circ}$ o.oo1). The level of agreement in classifying low, moderate and high risk patients between the Framingham score and the D.A.D score was $71.2 \%$ ( $\kappa=0.19$ CI: $\left.0.09-0.29 ; p^{\circ} 0.001\right)$. The SCORE risk and the WHO score showed respectively an agreement level of $89.6 \%(\kappa=$ o.28 CI: $\left.0.12-0.43 ; p^{\circ} 0.001\right)$ and $83.9 \%(\kappa=0.21$ CI: o.06-0.35; $p^{\circ}$ o.001) with the D.A.D score. Conclusion: The overall CVR estimated by the different CVR estimation scores allowed us to highlight a low prevalence of PLWHIV with high CVR. The WHO clinical CVR estimation scale could be a low cost alternative to evaluate CVR in resource-limited countries such as Togo.

Keywords: cardiovascular risk, HIV, framingham, D.A.D, score, togo.

Author $\alpha \sigma \rho \boxminus \times \zeta$; Department of Internal Medicine, University of Lome, Lome, Togo.

¥: Department of Cardiology, University of Lome, Lome, Togo.

§: Department of Nephrology and Hemodialysis, University of Lome, Lome, Togo

$\varepsilon \theta$ : Department of Infectious and Tropical diseases, University of Lome, Lome, Togo

$\alpha$ ø: Members of Diabetes Academic Africa (D2A).

\section{INTRODUCTION}

The World Health Organization (WHO) estimates that 17.7 million deaths worldwide are attributable to cardiovascular diseases (CVD), accounting for $31 \%$ of total global mortality in 2015[1]. Between 1990 and 2013, Sub-Saharan 
Africa recorded an $81 \%$ increase in the number of CVD deaths [2]. At the same time, this same region of Africa is facing another scourge, that of HIV/AIDS. Indeed, in 2018, it is estimated that sub-Saharan Africa was home to 2/3 of the 37.9 million people living with HIV (PLWHIV) in the world [3]. Thanks to active screening and increased access to Highly Active Antiretroviral Therapy (HAART), the life expectancy of PLWHIV has been steadily increasing [3,4]. The average age of PLWHIV is increasing but with new challenges such as non-communicable diseases, especially CVD $[5,6]$. According to published data, the risk of cardiovascular events is twice as high among PLWHIV compared to HIV-negative people $[7,8]$ and this at younger ages [6]. Explanations for this high CVD risk are HIV-related chronic arterial inflammation on the one hand [9,10] and HAART [11] on the other hand, which exposes PLWHIV to dyslipidemia $[12,13]$, lipid distribution disorders [14] and carbohydrate metabolism disorders [14-16] thus increasing their risk of atherosclerosis and metabolic syndrome [17].

According to the recommendations of the WHO, global cardiovascular risk (CVR) evaluation is a prerequisite for the institution of any primary prevention intervention for CVD [18]. Several cardiovascular risk evaluation scales exist as tools for this purpose, the best known of which is the Framingham score but also the Systematic Coronary Risk Evaluation (SCORE) proposed by the European Society of Cardiology [19]. In sub-Saharan Africa, the WHO proposes two CVR evaluation tables; one that takes into account clinical data and cholesterol levels and the other that takes into account only clinical parameters [20].

However, it must be recognized that the three above-mentioned scores were developed from a general population and none of the three takes into account in their CVR estimation, variables specific to HIV infection such as current HAART molecules, CD4 count, viral load, duration of HIV infection, duration of exposure to HAART.

The D.A.D study (Data collection on Adverse effects of anti-HIV Drugs) made it possible to develop an algorithm for calculating the overall CVR and is considered the currently available reference score in terms of cardiovascular risk evaluation specific to PLWHIV [21].

The objective of our work was first to evaluate the overall cardiovascular risk of PLWHIV in Togo according to the Framingham score, SCORE, the WHO scale (dedicated to sub-Saharan African countries based on clinical data only), D.A.D and then compare the three scores based on the general population with the PLWHIV-specific score. The ultimate research question, being to know at the practical level which of the three Framingham, SCORE, WHO, scores could be an alternative tool to the D.A.D to evaluate overall CVR among PLWHIV in resource-constrained settings.

\section{METHOD}

\subsection{Presentation of the study site}

The Ambulatory Treatment Center (ATC) of the Infectious Diseases Department of the Sylvanus Olympio University Hospital in Lome (CHU-SO) served as the framework for our study. It is the reference service for the care of PLWHIV in Togo. Approximately three thousand five hundred patients are regularly followed up with HAART.

\subsection{Type and period of study}

We conducted a cross-sectional descriptive and analytical study on patients under HAART received in consultation for their routine follow-up and newly screened PLWHIV who were initiated on HAART from May 1, 2019 to October 31,2019 , i.e. a period of six months.

\subsection{Study population}

The inclusion criteria for our study were:

- Any clinically stable PLWHIV on HAART received in follow-up consultation during the study period, aged at least 40 years old regularly followed for at least six months at the ATC of CHU SO, not having missed any follow-up appointment during the six month preceding the day of consultation. 
- All PLWHIV naïve to HAART, referred for HAART initiation consultation during the study period.

- To have the results of a blood test no more than three months old consisting of a serum assay of total cholesterol (CT), triglycerides (TG), HDL- cholesterol (HDL-c), LDLcholesterol ( LDL-c), CD4 count and a recent viral load (CV) measurement.

The following were excluded from our study:

- Patients with a personal history of angina, myocardial infarction or stroke.

- Patients on hormonal treatment, on lipid-lowering treatment.

- Patients with thyroid disease.

- Any patient presenting a situation that could lead to an increase in abdominal volume and distort the measurement of waist circumference (pregnant woman, liver pathology with ascites).

- Breastfeeding women.

- Patients who refused to participate in the study.

Patients on HAART were randomly recruited at a rate of 15 patients per week during follow-up visits. All naïve patients who met the inclusion criteria were selected.

\section{DATA COLLECTION AND SOURCES}

A standardized data collection sheet was designed and used as a support for data collection. Patients were informed in advance of the data collection process. Age, sex, notions of hypertension and diabetes and HIV history, were collected through interviews and the patient's treatment record. Waist circumference was measured with a tape measure wrapped around the waist by the midpoint between the lower edge of the rib and the iliac crest in a plane perpendicular to the major axis of the body. The size was determined without shoes using a measuring rod. The weight was measured using a bathroom scale. Body mass index (BMI) was calculated as the ratio of weight to height squared. A BMI greater than $25 \mathrm{~kg} / \mathrm{m}^{2}$ defined overweight. The high waist circumference corresponding to abdominal obesity was defined according to the criteria of the International Diabetes Federation (waist circumference greater than or equal to $94 \mathrm{~cm}$ in men and $80 \mathrm{~cm}$ in women). Blood pressure was measured for each patient with a mercury manometer twice after 10 minutes of rest. The mean systolic and diastolic figures obtained from both measurements were included in the evaluation of high blood pressure.

Hypertension was defined as systolic blood pressure (SBP) $\geq 140 \mathrm{mmHg}$ and / or diastolic blood pressure (DBP) $\geq 90 \mathrm{mmHg}$ or a known history of hypertension or the use of antihypertensive drugs[22].

The existence of dyslipidemia was defined according to the criteria of the National Cholesterol Education Program, Adult Treatment Panel III which are: total hypercholesterolemia (HCT) if $\mathrm{CT} \geq 2.0 \mathrm{~g} / \mathrm{L}$, hypertriglyceridemia (HTG) if TG $\geq 1.5 \mathrm{~g} / \mathrm{L}, \mathrm{HDL}$ hypocholesterolemia $(\mathrm{HCH})$ if HDL-c ${ }^{<} 0.5 \mathrm{~g} / \mathrm{L}$ in women and ${ }^{<} 0.4 \mathrm{~g} / \mathrm{L}$ in men, LDL hypercholesterolemia (HCL) if LDL-c $\geq 1.3 \mathrm{~g} / \mathrm{L}$.

\subsection{Cardiovascular risk evaluation}

The cardiovascular risk was estimated for each patient included in the study using four equations to calculate the overall risk of cardiovascular disease (CVD): the Anderson-Framingham CVR score, the Systematic Coronary Risk Evaluation (SCORE), the WHO CVR score dedicated to the western region of Sub-Saharan Africa where Togo is located and the CVD risk equation for PLWHIV derived from the D.A.D cohort.

The Anderson-Framingham equation (FRS) estimates in subjects aged 30 and older the risk of occurrence of CVD at 10 years based on the combination of CVR factors namely age, sex, systolic blood pressure, the use or not of an antihypertensive treatment, the values of the serum total cholesterol level, HDL-c, the existence of active smoking or not, the existence or not of diabetes [23]. Patients are classified into three levels of CVR: low risk ('10\%), moderate (10-20\%), high (> 20\%).

The European Society of Cardiology's SCORE risk estimates 10-year mortality from cardiovascular event in subjects aged 40 and over and is based on sex, age, systolic blood pressure, whether or not 
there is active smoking and total cholesterol level. Patients are classified as low $(<3 \%)$, moderate $(\geq$ $3 \%$ and $<5 \%$ ), high ( $\geq 5$ to $<10 \%$ ) and very high risk ( $\geq 10 \%$ ). For our study, high and very high risk patients were grouped into a single "High Risk " group ( $\geq 5 \%$ ) to simplify comparisons. With regard to the incidence of coronary heart disease in Togo, we opted for the SCORE table based on the European Society of Cardiology of 2019 recommendations for European countries with low CVR [19].

The WHO CVD risk score for the western region of Sub-Saharan Africa used for our study makes it possible to estimate in subjects aged 40 and over, the 10-year risk of a fatal cardiovascular event (myocardial infarction, cerebrovascular accident, or any other arterial occlusive disease including sudden death by cardiac arrest) taking into account only clinical parameters, namely sex, age, smoking status, body mass index and systolic blood pressure[24]. Given the context of limited resources in this region where Togo is located, we opted for this score because in practice, PLWHIV often have difficulties in honoring on time the unsubsidized biochemical check-ups that they are supposed to honor once a year. According to the WHO score, patients are classified into three levels of cardiovascular risk: low ( $10 \%)$, moderate (10-20\%), high (> 20\%) risk.

In order to ensure consistency in the evaluation of CVR, the CVR evaluation according to the D.A.D equation was also evaluated over 10 years. We referred for this purpose to the D.A.D algorithm published by Nina Friis-Møller et al [25]. The equation is based on the combination of age, gender, systolic blood pressure, serum CT and HDL-c level, known or unknown diabetes, active or inactive smoking status, family history of cardiovascular disease, current use of Abacavir, Indinavir or Lopinavir, and number of years spent on Indinavir or Lopinavir. The family history of CVD was defined as the first degree occurence of CVD before age 50 in men and 65 in women [21].

\subsection{Statistical analysis of data}

All of the data collected was entered into a data entry mask developed in Epi data version 3.1 software and then analyzed using IBM SPSS Statistics 20 statistical software.

Continuous quantitative variables with a normal distribution were expressed as mean and standard deviations if not as medians and interquartile ranges (IQR). Categorical variables were expressed as percentages.

The $\chi 2$ test or Fisher's test was used to compare the proportions. Pearson's correlation test was used to evaluate the degree of correlation between the risk scores obtained according to each algorithm while the agreement between CVD risk evaluation equations was evaluated using Cohen's Kappa coefficient with a 95\% confidence interval. A p-value 0.05 was considered statistically significant. The Kappa coefficient was interpreted as having bad agreement $(<0)$, slight agreement (0-0.20), fair agreement (0.21-0.40), moderate agreement (0.41-0.60), substantial agreement (0.61-0.80) or perfect agreement (o.81-1.00) [26].

\subsection{Ethical considerations}

The authorization of the head of the Ambulatory Treatment Center for HIV-infected people has been obtained. Informed consent of the patients was obtained. The anonymity and confidentiality of their data were respected.

\section{RESULTS \\ 4.1 General characteristics of the study population}

Two hundred and twelve patients were included in our study. Females predominated in a proportion of $68.9 \%$ (146) with an M / F sex ratio of 0.45 . The median age was 50.2 years (IQR: 44.8-56.0) with a minimum of 40 years and a maximum of 72 years. The 40 to 49.9 age group was the most represented in $48.1 \%$. Almost half of our study population (47.6\%) made a living from commerce and were married (48.6\%). Eighty-three point five percent (177 patients) of our study population resided in urban areas. The median time since diagnosis of HIV status was 4.1 years (IQR: 2.7-7.2) with a minimum of 1 year and a maximum of 14.4 years. Eight patients (3.8\%) 
were known to have diabetes and 35 (16.5\%) were hypertensive. The notion of active smoking was found in 10 patients, i.e. $4.7 \%$. None of the patients in the sample reported a family history of CVD.

Patients on HAART represented a proportion of $87.7 \%$ (186). Their median duration on HAART was 3.6 years (IQR: 2.7-7.3). Among patients on HAART, patients on 1st line made of a combination of two Nucleoside Reverse Transcriptase Inhibitors (NRTIs) and one Non-Nucleoside Reverse Transcriptase Inhibitor (NNRTI) accounted for $87.1 \%$ (162) while the remainders were on a combination of two NRTIs and a Protease Inhibitor (PI). With Lamivudine as the common molecule in all combinations, the distribution of patients according by exposure to different ARV molecules was as follows: Tenofovir (90.9\%), Abacavir (8.1\%), Zidovudine (1.1\%), Efavirenz (86.6\%), Nevirapine (0.5\%), Atazanavir boosted with Ritonavir (12.9\%). One hundred and ninety-seven patients or $92.9 \%$ of the study population had a recent $\mathrm{CD} 4$ count while $83 \%$ (176) had a recent viral load measurement. The mean CD4 count was 462 cells $/ \mathrm{mm}^{3}( \pm 252)$ and the proportion of patients with a $\mathrm{CD} 4$ count greater than 500 cells / $\mathrm{mm}^{3}$ was $41.1 \%$ (81 patients). The proportion of patients with suppressed viral load represented $84.1 \%$ (148). The remaining characteristics of the study population are presented in Table 1.

Table 1: Socio demographic and HIV infection characteristics of the study population.

\begin{tabular}{|c|c|}
\hline Characteristics & Values \\
\hline Age [Years (IQR)] & $50.2(44.8-56.0)$ \\
\hline \multicolumn{2}{|l|}{ Age groups in Years n (\%) } \\
\hline $40-49 \cdot 9$ & $102(48.1)$ \\
\hline $50-59 \cdot 9$ & $82(38.7)$ \\
\hline $60-69.9$ & $25(11.8)$ \\
\hline$\geq 70$ & $3(1.4)$ \\
\hline \multicolumn{2}{|l|}{ Gender, n (\%) } \\
\hline Male & $66(31.1)$ \\
\hline Female & 146 (68.9) \\
\hline \multicolumn{2}{|l|}{ Occupation, n (\%) } \\
\hline Traders & $101(47.6)$ \\
\hline Others & $35(16.6)$ \\
\hline State officials & $23(10.8)$ \\
\hline Unemployed & $18(8.5)$ \\
\hline Retirees & $18(8.5)$ \\
\hline Employees in the private sector & $17(8.0)$ \\
\hline \multicolumn{2}{|l|}{ Marital status, $\mathrm{n}(\%)$} \\
\hline Married & $103(48.6)$ \\
\hline Widowed living alone & $42(19.8)$ \\
\hline Single & $36(17.9)$ \\
\hline Divorced & $29(13.7)$ \\
\hline Widowed remarried & $2(0.9)$ \\
\hline \multicolumn{2}{|l|}{ Education level, n (\%) } \\
\hline None & $65(30.6)$ \\
\hline Primary & $60(28.3)$ \\
\hline Secondary & $77(36.4)$ \\
\hline Higher study & $10(4.7)$ \\
\hline
\end{tabular}

Cardiovascular Risk Factors and Cardiovascular Risk in People Living with HIV: Comparison of Four Cardiovascular Risk Prediction Algorithms 


\begin{tabular}{|c|c|}
\hline Residential area, n (\%) & \\
\hline Urban & $177(83.5)$ \\
\hline Rural & $35(16.5)$ \\
\hline Smoker, n (\%) & $10(4.7)$ \\
\hline History of Diabetes, $\mathrm{n}(\%)$ & $8(3.8)$ \\
\hline History of HBP, n (\%) & $35(16,5)$ \\
\hline HAART exposure, n (\%) & \\
\hline Naifs-HAART & $26(13.3)$ \\
\hline HAART-exposed & $186(87.7)$ \\
\hline HAART regimen, n (\%) & \\
\hline 2NRTIs+1NNRTIs & $162(87.1)$ \\
\hline 2NRTIs+1IPs & $24(12.9)$ \\
\hline TDF Exposed, n (\%) & 169 (90.9) \\
\hline AZT Exposed, n (\%) & $2(1.1)$ \\
\hline ABC Exposed, n (\%) & $15(8.1)$ \\
\hline EFV Exposed, n (\%) & $161(86.6)$ \\
\hline NEV Exposed, n (\%) & $1(0.5)$ \\
\hline ATV(r) Exposed, n(\%) & $24(12.9)$ \\
\hline Median duration of HAART exposure [Years (IQR)] & $3.6(2.7-7.1)$ \\
\hline Median duration since HIV diagnostic [Years (IQR)] & $4.1(2.7-7.2)$ \\
\hline $\mathrm{CD} 4$ count $\mathrm{cel} / \mathrm{mm}^{3}, \mathrm{mean} \pm \mathrm{SD}$ & $462( \pm 252)$ \\
\hline CD4 count $\geq 5$ oocel/ mm $^{3}, \mathrm{n}(\%)$ & $81 / 197(41.1)$ \\
\hline Viral load suppressed, n (\%) & $148 / 176(84.1)$ \\
\hline
\end{tabular}

ABC: Abacavir; ATV(r): Atazanavir boosted by Ritonavir; AZT: Zidovudine; BMI : Body Mass Index; EFV: Efavirenz; HAART: Highly active antiretroviral therapy; HBP: High Blood Pressure; IPs :Protease Inhibitors; NEV: Névirapine; NNRTIs: Non-nucleoside reverse transcriptase inhibitors; NRTIs: Nucleoside reverse transcriptase inhibitors ; SD: Standard deviation; IQR: Interquartile range

\subsection{Cardiovascular risk factors Data}

The median waist circumference was $85.5 \mathrm{~cm}$ (IQR: 79-93.2). The average body mass index was $23.9 \mathrm{Kg} / \mathrm{m}^{2}( \pm 4.5)$. Among the cardiovascular risk factors, abdominal obesity was the most represented in $56.1 \%$ followed by $\mathrm{HCH}$ in $52.4 \%$ and hypertension in $44.8 \%$ (Table 2). Seventy-two point five percent of the patients had at least one dyslipidemia. Patients whose body mass index was $\geq 25 \mathrm{Kg} / \mathrm{m}^{2}$ accounted for $36.3 \%$. Women had significantly more abdominal obesity ( $p^{<}$o.001), more overweight ( $\mathrm{p}^{<}$0.001), more $\mathrm{HCH}$ ( $p^{\circ}$ o.001) and were more likely to have dyslipidemia $(p=0.016)$ than men. There was no significant gender difference in the frequencies of hypertension, HTG, HCT, HCL (Table 2).

Table 2: Characteristics of cardiovascular risk factors

\begin{tabular}{|c|c|c|c|c|}
\hline & Overall $(\mathrm{n}=212)$ & Male $(\mathrm{n}=66)$ & Female $(\mathrm{n}=146)$ & $\mathrm{p}$-value \\
\hline $\begin{array}{c}\text { Waist circumference [cm } \\
(\mathrm{IQR})]\end{array}$ & $85.5(79-93.2)$ & $82.3(79-90)$ & $87.5(80-94)$ & 0.019 \\
\hline Abdominal obesity, n (\%) & $119(56.1)$ & $12(10.1)$ & $107(89.9)$ & '0.001 \\
\hline SBP[mmHg (IQR)] & $130(120-144)$ & $131.5(123-139)$ & $129(118-146)$ & $\mathrm{NS}$ \\
\hline
\end{tabular}

Cardiovascular Risk Factors and Cardiovascular Risk in People Living with HIV: Comparison of Four Cardiovascular Risk Prediction Algorithms 


\begin{tabular}{|c|c|c|c|c|}
\hline $\mathrm{DBP}[\mathrm{mmHg}(\mathrm{IQR})]$ & $84(76-93)$ & $84(78-93)$ & $83(76-94)$ & NS \\
\hline HTA, n (\%) & $95(44.8)$ & $25(37.9)$ & $70(47.9)$ & NS \\
\hline $\mathrm{BMI}\left(\mathrm{Kg} / \mathrm{m}^{2}\right)$, mean $\pm \mathrm{SD}$ & $23.9( \pm 4.5)$ & $22.3( \pm 3.3)$ & $24.6( \pm 4.8)$ & 0.001 \\
\hline \multicolumn{5}{|l|}{$\begin{array}{c}\text { BMI Classification }\left(\mathrm{Kg} / \mathrm{m}^{2}\right) \text {, } \\
\mathrm{n}(\%)\end{array}$} \\
\hline${ }^{\circ} 18,5$ & $21(9.9)$ & $7(3 \cdot 3)$ & $14(6.6)$ & \multirow{5}{*}{0.012} \\
\hline $18.5^{-24.9}$ & $114(53.8)$ & $45(21.2)$ & $69(32.5)$ & \\
\hline $25-29.9$ & $61(28.8)$ & $14(6.6)$ & $47(22.2)$ & \\
\hline $30-34,9$ & $9(4.2)$ & $\mathrm{O}(0.0)$ & $9(4.2)$ & \\
\hline $35-39,9$ & $7(3.3)$ & $\mathrm{o}(0.0)$ & $7(3.3)$ & \\
\hline $\mathrm{CT}[\mathrm{g} / \mathrm{l}(\mathrm{IQR})]$ & $1.8(1.6-2.1)$ & $1.78(1.4-2.1)$ & $1.84(1.6-2.1)$ & NS \\
\hline HDL-c [g/l(IQR)] & $0.5(0.4-0.5)$ & $0.5(0.4-0.5)$ & $0.5(0.4-0.5)$ & NS \\
\hline LDL-c [g/l(IQR)] & $1.16(0.9-1.4)$ & $1.14(0.8-1.4)$ & $1.17(1.0-1.6)$ & NS \\
\hline TG [g/l(IQR)] & $0.9(0.6-1.2)$ & $0.9(0.7-1.3)$ & $0.9(0.6-1.1)$ & NS \\
\hline Glycemia [g/l(IQR)] & $0.9(0.8-1.0)$ & $0.9(0.8-1.0)$ & $0.9(0.8-1.2)$ & NS \\
\hline \multicolumn{5}{|l|}{$\begin{array}{l}\text { HDL-c } 0.4 \mathrm{~g} / \mathrm{l} \text { in men and } \\
0.5 \mathrm{~g} / \mathrm{l} \text { in women }\end{array}$} \\
\hline Yes & $111(52.4)$ & $21(18.9)$ & $90(81.1)$ & 0.001 \\
\hline \multicolumn{5}{|l|}{$\mathrm{TG} \geq 1.5 \mathrm{~g} / \mathrm{l}, \mathrm{n}(\%)$} \\
\hline Yes & $24(11.3)$ & $10(41.7)$ & $14(58.3)$ & NS \\
\hline \multicolumn{5}{|l|}{ LDL-c $\geq 1.3 \mathrm{~g} / \mathrm{l}, \mathrm{n}(\%)$} \\
\hline Yes & $66(31.1)$ & $21(31.8)$ & $45(68.2)$ & NS \\
\hline \multicolumn{5}{|l|}{$\mathrm{CT} \geq 2.0 \mathrm{~g} / \mathrm{l}, \mathrm{n}(\%)$} \\
\hline Yes & $64(30.2)$ & $20(31.2)$ & $44(68.8)$ & NS \\
\hline Any dyslipidemia, n (\%) & $148 / 204(72.5)$ & $40(27.0)$ & $108(72.9)$ & 0.016 \\
\hline
\end{tabular}

BMI: Body Mass Index; CT: Total Cholesterol; DBP: Diastolic Blood Pressure; HDLc: HDL- Cholesterolemia; IQR: Interquartile range; LDLc: LDL Cholesterolemia; NS: Not significant; SBP: Systolic Blood Pressure; SD: Standard deviation; TG: Triglyceridemia.

\subsection{Cardiovascular risk Evaluation and level of agreement between the different scores}

Median CVR was 6.3\% (IQR: 3.9-11.2), 0.0\% (IQR: 0.0-1.0), 4.0\% (IQR: 3.0-8.0), 3.0\% (IQR: 1.95-5.01), based on Framingham score, SCORE risk, WHO score and D.A.D score respectively. The overall cardiovascular risk evaluation ranked $8 \%$ of patients at high cardiovascular risk, $25 \%$ at moderate risk and $67 \%$ at low risk according to the Framingham score. The distribution according to SCORE was $6.1 \%$ of patients classified at high risk, $3.3 \%$ at moderate risk and $90.6 \%$ at low risk. The WHO risk score classified $5.2 \%$ high risk, $10.8 \%$ moderate risk and $84 \%$ low risk. Finally, the D.A.D score classified $1.5 \%$ of patients as high cardiovascular risk, $4.2 \%$ as moderate risk and 94.3\% as low risk. (Table 3). 
Table 3: Distribution of the study population according to the different cardiovascular risk scores

\begin{tabular}{|c|c|c|c|c|c|}
\hline \multicolumn{2}{|c|}{} & $\begin{array}{c}\text { Framin } \\
\text { gham } \\
(\mathrm{N}=212)\end{array}$ & $\begin{array}{c}\text { ESC/SC } \\
\text { ORE } \\
(\mathrm{N}=212)\end{array}$ & $\begin{array}{c}\text { WHO non } \\
\text { laboratory } \\
\text { based charts } \\
\text { for Western } \\
\text { Sub-Saharan } \\
\text { Africa (N=212) }\end{array}$ & $\begin{array}{c}\text { D.A.D } \\
\text { (N=212) }\end{array}$ \\
\hline \multirow{4}{*}{$\begin{array}{c}\text { Risk } \\
\text { level }\end{array}$} & $\begin{array}{c}\text { Low, n (\%) } \\
\text { n (\%) }\end{array}$ & $\begin{array}{c}142 \\
(67.0)\end{array}$ & $\begin{array}{c}192 \\
(90.6)\end{array}$ & $178(84.0)$ & $200(94.3)$ \\
\cline { 2 - 7 } & $\begin{array}{c}\text { High, n } \\
(25.0)\end{array}$ & $7(3.3)$ & $23(10.8)$ & $9(4.2)$ \\
\hline
\end{tabular}

D.A.D : Data Collection on Adverse Effects of Anti-HIV Drugs; WHO: World Health Organisation; ESC/SCORE: Systematic Coronary Risk Evaluation of European Society of Cardiology.

There was a strong positive and statistically significant correlation between the CVR scores based on the general population and the scores obtained according to the D.A.D algorithm as illustrated in Figure 1: Framingham and D.A.D $\left(\mathrm{r}=0.80 ; \mathrm{p}^{<} \mathrm{0.001}\right)$; SCORE and D.A.D ( $\mathrm{r}=0.58$; $\mathrm{p}^{<}$0.001) ; OMS and D.A.D ( $\left.\mathrm{r}=0.65 ; \mathrm{p}^{<} 0.001\right)$.

The level of agreement between the Framingham score and the D.A.D score was $71.2 \%(\kappa=0.19 \mathrm{CI}$ : 0.09-0.29; p 0.001). The SCORE risk and the WHO score presented respectively with the D.A.D score a level of agreement of $89.6 \%(\kappa=0.28 \mathrm{CI}$ : $\left.0.12-0.43 ; p^{<} 0.001\right)$ and $83.9 \%(\kappa=0.21 \mathrm{CI}$ : o.06-0.35; $\mathrm{p}^{\circ} \mathrm{o.001}$ ) as shown in Table 4.

\section{DISCUSSION}

Very few studies on the evaluation of CVR in PLWHIV exist in Africa, especially those that compare CVR estimation scores specific to the population of PLWHIV with CVR estimation scores used in practice for the general population. The originality of our study lies in two aspects: firstly, to our knowledge, our study is the first of its kind to evaluate CVR among PLWHIV in Togo but also it is the first in Togo to compare, within an African population of PLWHIV, three CVR estimation scores developed for a general population with a score specific to PLWHIV.
The median age in our sample was 50.2 years (IQR: 44.8-56.0). Our result is close to that of Muiru et al. in Uganda [27] and Begovac et al. in Serbia [28] who reported median ages of 49 years in their respective series. However, our median age was higher than that reported in Turkey by Korten et al. i.e. 48 years [29].

Cardiovascular risk factors, the most represented in our study were abdominal obesity with a frequency of $56.1 \%$, followed by $\mathrm{HCH}$ in $52.4 \%$ of cases and hypertension in $44.8 \%$. The frequency of abdominal obesity that we objectified is higher than that reported by Edward et al. in Nigeria [30], Mashinya et al. in South Africa [31] who reported $13.1 \%$ and $23.9 \%$ respectively. In contrast, Policarpo et al. reported a significantly higher frequency of abdominal obesity of $46.7 \%$ in subjects over 40 years of age compared to patients under 40 years of age, $25.4 \%$ of whom were abdominally obese [32]. Contrary to our study where $\mathrm{HCH}$ was the second most represented CVD risk factor, it occupied the first place in the series of Mashiya et al. and Edward et al. with lower rates of $43.8 \%$ and $49.8 \%$ respectively and a higher rate in the series by Nery et al. i.e. $61.9 \%[30,31,33]$. The variabilities in the literature relating to abdominal obesity and dyslipidemias could be attributed to genetic variability and different diets specific to the different ethnic groups included in the studies. This is the case of hypertriglyceridemia found at low rates in our 
study (11.6\%) also reported in other African studies $[30,31,34]$ and which contrasts with high rates ranging from $36.4 \%$ to $61.4 \%$ in non-African studies [32,33]. There is a triglyceride paradox that may explain why blacks and people of African descent tend to have a low prevalence of HTG despite the presence of a high frequency of $\mathrm{HCH}$ [35]. One of the explanations would be hyperactivity of the lipoprotein lipase whose activity is not inhibited by insulin resistance and the low level of apolipoprotein CIII whose activity inhibits lipoprotein lipase activity in black compared to Caucasian [36].
The frequency of arterial hypertension that we have objectified was above the prevalence of hypertension reported in Togo in the general population which varies between 25 and $36.7 \%$ [37-39] and slightly exceeded the prevalence of hypertension in sub-Saharan Africa [40]. Begovac et al. in Serbia, Policarpo et al. in Portugal, and Korten et al. in Turkey reported in their series on PLWHIV subjects aged 40 and above, hypertension frequencies lower than our result, namely $31.5 \%, 24 \%, 22 \%$ respectively [28,29,32].
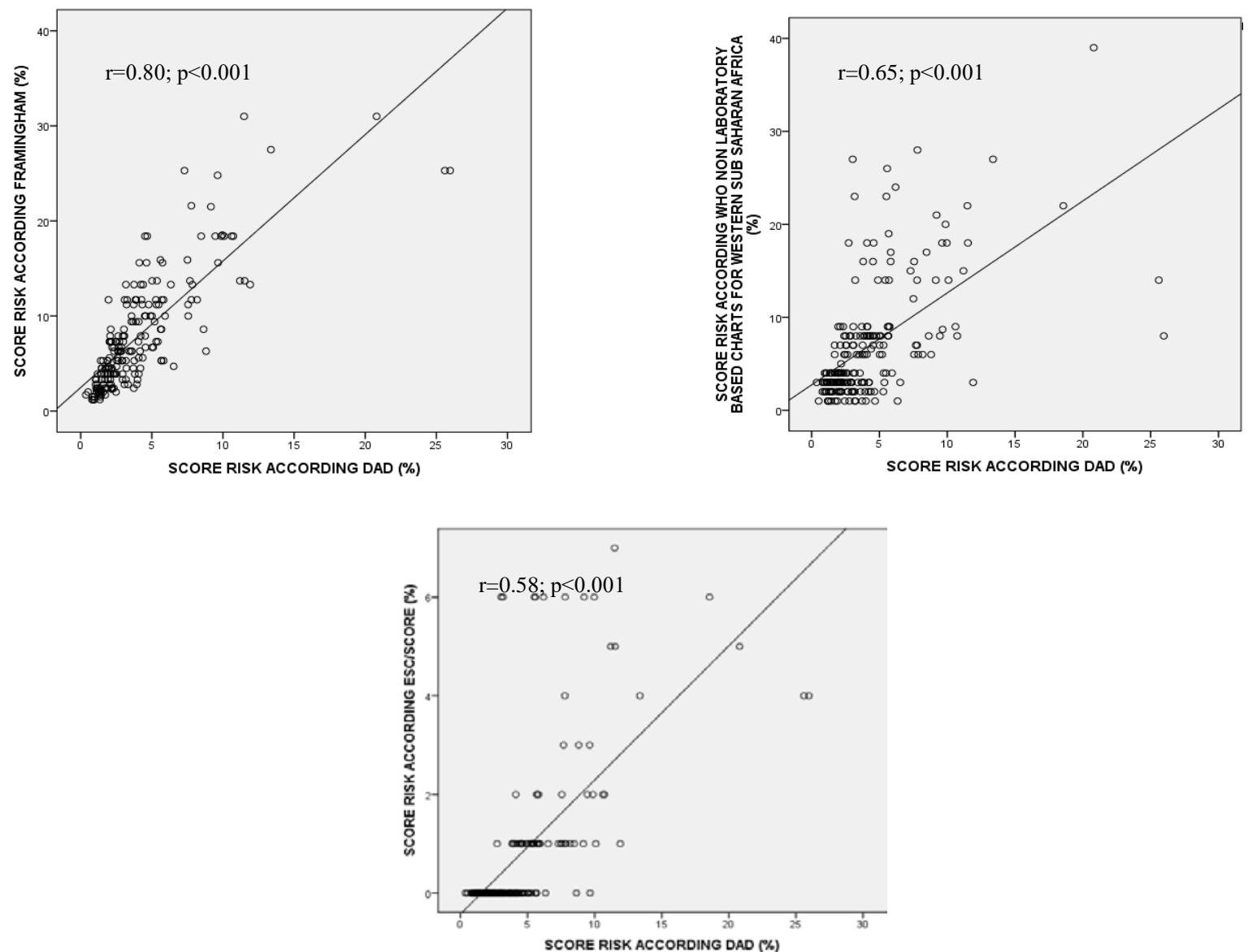

Figure 1: Correlation study between cardiovascular risks according to DAD with the FRAMINGHAM score the WHO score and the SCORE score 
Table 4: Assessment of the level of agreement between the Framingham score, SCORE, OMS and the D.A.D score

\begin{tabular}{|c|c|c|c|c|c|c|c|c|c|c|}
\hline \multirow{2}{*}{$\frac{\text { Cardiovascular }}{\text { disease risk }}$} & & \multicolumn{3}{|c|}{ Framingham (N=212) } & \multicolumn{3}{|c|}{ ESC/ SCORE (N=212) } & \multicolumn{3}{|c|}{$\begin{array}{l}\text { WHO non laboratory based charts for Western } \\
\text { SubSaharan Africa }(\mathrm{N}=212)\end{array}$} \\
\hline & & $\begin{array}{l}\text { Low } \\
\text { risk }\end{array}$ & Moderate & High & Low risk & Moderate & High & Low risk & Moderate & High \\
\hline \multirow{3}{*}{ D.A.D $(\mathrm{N}=212)$} & Low risk & 142 & 47 & 11 & 188 & 4 & 8 & 174 & 19 & 7 \\
\hline & Moderate & 0 & 6 & 3 & 4 & 1 & 4 & 3 & 3 & 3 \\
\hline & High & 0 & 0 & 3 & 0 & 2 & 1 & 1 & 1 & 1 \\
\hline Agreement & & & $71.2 \%$ & & & $89.6 \%$ & & & $83.9 \%$ & \\
\hline Kappa (p-value) & & & $\begin{array}{c}0.19 \\
(<0.001)\end{array}$ & & & $\begin{array}{c}0.28 \\
(<0.001)\end{array}$ & & & $\begin{array}{c}0.21 \\
(<0.001)\end{array}$ & \\
\hline 95\%IC & & & $0.09-0.29$ & & & $0.12-0.43$ & & & $0.06-0.35$ & \\
\hline
\end{tabular}

D.A.D : Data Collection on Adverse Effects of Anti-HIV Drugs; WHO: World Health Organisation

This high frequency of hypertension in our series could be explained by the stress to which the majority of patients in our study are exposed, firstly with regard to their sectors of activity which are based on small informal businesses that are unstable in terms of income but also because of the fear of the stigmatization linked to the status of PLWHIV which puts them in a situation of psychological tension each time they have to go to the hospital to renew their HAART. Indeed, stress and socio-professional categories have been reported to be associated with hypertension [41,42]. In addition, etiopathogenic predispositions related to lower renin activity, a high water-sodium retention coefficient and a probable higher prevalence of hyperaldosteronism have been reported as possible explanations for the susceptibility of the sub-saharan African subject to develop hypertension [43-48].

According to our results, CVR was high in $8 \%$ of the study population according to the FRS score, in $6.1 \%$ according to SCORE while the D.A.D score categorized $1.5 \%$ of the study population with high CVR. These rates reveal a low prevalence of subjects with high CVR in our sample. The estimated CVRs in the literature vary greatly depending on the estimation scores that were used. Indeed, the majority of studies in the literature have compared the 5-year estimated CVR according to D.A.D with the 10-year absolute CVR of the general population equations
(Framingham, PROCAM, SCORE). Because the change over time in absolute CVR is not entirely linear, CVR based on estimation scales with different time projection variables may generate a lower probability of a perfect match leading to possible estimation biases [34].

However, it can be noted that some authors have reported, as we have, low rates of patients with high CVR in their series. This is the case of Noumegni et al. in Cameroon who reported in their series a proportion of RCV according to FRS close to our result (8.4\%) and a slightly high proportion of $2.4 \%$ according to D.A.D [34]. Also in Brazil, Nery et al. reported low frequencies of subjects with high CVR: $2.8 \%$ according to FRS and $2.1 \%$ according to D.A.D [33]. In contrast, Begovac et al. in Serbia reported high frequencies of subjects with high CVR namely $27.16 \%$ according to FRS, $31.49 \%$ according to SCORE, and $51.6 \%$ according to D.A.D [28]. Similarly, Dhillon et al. in the United Kingdom reported high frequencies of subjects with high CVR of $21.5 \%$ according to FRS and $14.8 \%$ according to D.A.D as well as Policarpo et al. in Portugal with 20.5\% according to FRS, $10.3 \%$ according to D.A.D, $4.4 \%$ according to SCORE $[32,49]$. The high rates of subjects with high CVR objectified by certain scores in these European studies could be explained by the high frequency of smoking $24.4 \%, 42.9 \%, 51.9 \%$ respectively in the studies by 
Dhillon et al., Begovac et al. and Policarpo et al. against $4.7 \%$ in our study.

Our study allowed us to demonstrate a strong positive correlation between the three CVR estimation scores reserved for the general population FRS, SCORE, WHO in the CVR estimation with the D.A.D. Noumegni et al. reported, as we did, a positive correlation between the FRS equation and D.A.D score.

However, despite the excellent continuous positive correlation displayed between the general scores and the D.A.D score, the level of agreement between the Framingham score and the D.A.D score was slight $(\kappa=0.19$ CI: 0.09-0.29; $\left.\mathrm{p}^{<} 0.001\right)$ while SCORE $(\kappa=0.28 \mathrm{CI}$ : $\left.0.12-0.43 ; \mathrm{p}^{<} 0.001\right)$ and the WHO CVR score $(\kappa=$ 0.21 CI: 0.06-0.35; $\mathrm{p}^{<}$0.001) showed a fair level of agreement. In contrast to our result, a fair level of agreement between the FRS score and the D.A.D score was reported by Nery et al. $(\kappa=0.23)$, Pirs et al. $(\kappa=0.24)$, Mashinya et al. $(\kappa=0.23)$, while a substantial level of agreement between these two scores was reported by Noumegni et al. $(\kappa=$ 0.61) [30.32.33.49]. For Pirs et al. the level of agreement was rather moderate $(\kappa=0.53)$ between SCORE and D.A.D [50].

The SCORE risk and the WHO rating scale showed approval rates of $89.6 \%$ and $83.6 \%$ respectively with the D.A.D score well above the 71.2\% approval rate of the FRS score. In addition, the WHO CVR estimation table categorized 5.2\% of the study population as having high RCV, a rate which is close to the rate estimated by SCORE (6.1\%). Based on these results, it can be suggested that the evaluation of the CVR according to the WHO, not taking into account laboratory data, may constitute an acceptable tool at a lower cost to estimate CVR in PLWHIV without cholesterol level measurement in low income countries such as Togo. However, if serum cholesterol measurement is available, evaluation using SCORE could be a suitable alternative. But, it should be kept in mind that out of the cumulative frequencies of patients classified as moderate and high CVR, $40 \%(8 / 20)$ and only $23.5 \%(8 / 34)$ respectively according to SCORE and WHO were finally classified as moderate and high CVR according to the D.A.D algorithm. This result shows that these two scores overestimate the CVR as well as the FRS, of which only $17.1 \%(12 / 70)$ of the cases classified as moderate and high risk were classified by D.A.D (Table 4). Noumegni et al. and Edwards-Jackson et al. also reported that the trend in FRS score, overestimated CVR in PLWHIV. In practice, this means that some patients may be classified as high CVR and excessively benefiting from intensive CVD prevention measures. This would expose patients to potential adverse drug reactions, but also to increased health costs. A solution that could sort this out for this purpose would be the measurement of media thickness / intima of the carotid artery, which would make it possible to identify among the subjects considered to be at moderate risk according to SCORE and the WHO estimation scale, those with a real high CVR. SCORE risk and the D.A.D scale have demonstrated a good ability to identify patients with subclinical atherosclerosis [50] although it should be noted that according to another study, D.A.D and SCORE underestimated the presence of subclinical atherosclerosis and that D.A.D outperformed SCORE in detecting subclinical atherosclerosis [51].

Our study has limitations that are worth noting. Firstly, the cross-sectional nature of our study does not allow us to establish a cause and effect relationship between the vascular risks estimated by the various scores that were the subject of our study and the actual cardiovascular events expected or which will occur. Only an observational study could answer this question. Secondly, our study was based on patients with unknown cardiovascular pathologies followed in an urban center. Thus, our sample may not be representative of the entire Togolese population living with HIV. Nevertheless, our study has the merit of being the first to attempt to evaluate CVR using four CVR scores. Therefore, its results constitute data that can be compared with those of middle and high income countries. Thirdly, our analysis only included patients aged 40 years and older, so the estimated frequencies of CVR could be different if younger subjects were included. 
However, the age range we used is the age range in which the different CVD risk equations were primarily developed and validated. Fourth, excluding patients on lipid-lowering drugs probably contributed to the exclusion of subjects with other potential CVD risk factors which may have lowered CVR levels. Finally, we did not evaluate fat distribution disorders, lipodystrophy and lipoatrophy that have been shown to be associated with elevated CVR.

\section{CONCLUSION}

The overall CVR estimated by the different CVR estimation scores allowed us to highlight a low frequency of PLWHIV with high CVR in our sample. However, high frequencies of wellknown CVD risk factors such as hypertension, $\mathrm{HCH}$, abdominal obesity to which are added the increase in the average age of PLWHIV require caregivers in charge of medical monitoring of PLWHIV not to content to only monitor the CD4 count and viral load but also to systematically take into account the evaluation of the global CVR in patients. To this end, as far as Togo is concerned, the WHO scale taking into account only the clinical parameters devoted to sub-Saharan Africa can be a very practical and low cost alternative tool. If, however, a measure of total serum cholesterol is available, the SCORE scale may be more appropriate. Detecting subjects with high CVR is essential in order to institute preventive measures to reduce risk, starting with the management of CVD factors and adopting a healthy lifestyle.

\section{Conflicts Of Interest:}

The authors declare that they have no conflict of interest.

\section{Thanksgiving:}

We would like to thank the team of the "Cabinet d'Expertise en Etudes et Traitements Statistiques (CEETS)" for their collaboration and assistance in the analysis and statistical processing of data.

\section{REFERENCES}

1. Cardiovascular diseases (CVDs) n.d. https:// www.who.int/fr/news-room/fact-sheets/det ail/cardiovascular-diseases-(cvds) (accessed March 16, 2020).

2. Ga M, Ga R, Uk S, Ae M, Vl F, Mh F, et al. Mortality from cardiovascular diseases in sub-Saharan Africa, 1990-2013: a systematic analysis of data from the Global Burden of Disease Study 2013. Cardiovasc J Afr 2015; 26:S6-10.https://doi.org/10.5830/CVJA-201 5-036.

3. Global HIV \& AIDS statistics - 2019 fact sheet n.d. https://www.unaids.org/en/ resources/fact-sheet (accessed January 21, 2020).

4. Lewden C, Bouteloup V, De Wit S, Sabin C, Mocroft A, Wasmuth JC, et al. All-cause mortality in treated HIV-infected adults with $\mathrm{CD} 4 \geq 500 / \mathrm{mm} 3$ compared with the general population: evidence from a large European observational cohort collaboration. Int $\mathrm{J}$ Epidemiol 2012;41:433-45. https://doi.org/ 10.1093/ije/dyr164.

5. Juma K, Nyabera R, Mbugua S, Odinya G, Jowi J, Ngunga M, et al. Cardiovascular risk factors among people living with HIV in rural Kenya: a clinic-based study. Cardiovasc J Afr 2019;30:52-6.https://doi.org/10.5830/CVJA $-2018-064$.

6. Triant VA, Lee H, Hadigan C, Grinspoon SK. Increased Acute Myocardial Infarction Rates and Cardiovascular Risk Factors among Patients with Human Immunodeficiency Virus Disease. J Clin Endocrinol Metab 2007; 92:2506-12.https://doi.org/10.1210/jc.20o62190.

7. Islam FM, Wu J, Jansson J, Wilson DP. Relative risk of cardiovascular disease among people living with HIV: a systematic review and meta-analysis. HIV Med 2012;13:453-68. https://doi.org/10.1111/j.1468-1293.2012.009 96.x.

8. Shah ASV, Stelzle D, Lee KK, Beck EJ, Alam S, Clifford S, et al. Global Burden of Atherosclerotic Cardiovascular Disease in People Living With HIV: Systematic Review and 
Meta-Analysis. Circulation 2018;138:1100-12. https://doi.org/1O.1161/CIRCULATIONAHA. 117.033369.

9. Duprez DA, Neuhaus J, Kuller LH, Tracy R, Belloso W, De Wit S, et al. Inflammation, coagulation and cardiovascular disease in HIV-infected individuals. PLoS ONE 2012; 7:e44454.https://doi.org/10.1371/journal.po ne.0044454.

10. Subramanian S, Tawakol A, Burdo TH, Abbara S, Wei J, Vijayakumar J, et al. Arterial Inflammation in Patients With HIV. JAMA 2012;308:379-86.

https://doi.org/10.10o1/jama.2012.6698.

11. Bavinger C, Bendavid E, Niehaus K, Olshen RA, Olkin I, Sundaram V, et al. Risk of Cardiovascular Disease from Antiretroviral Therapy for HIV: A Systematic Review. PLOS ONE 2013;8:e59551. https://doi.org/10.1371/ journal.pone.0059551.

12. Grunfeld C. Dyslipidemia and its Treatment in HIV Infection. Top HIV Med Publ Int AIDS Soc USA 2010;18:112-8.

13. Grunfeld C, Pang M, Doerrler W, Shigenaga JK, Jensen P, Feingold KR. Lipids, lipoproteins, triglyceride clearance, and cytokines in human immunodeficiency virus infection and the acquired immunodeficiency syndrome. $\mathrm{J}$ Clin Endocrinol Metab 1992;74:1045-52.

https://doi.org/10.1210/jcem.74.5.1373735.

14. Hadigan C, Meigs JB, Corcoran C, Rietschel $\mathrm{P}$, Piecuch S, Basgoz N, et al. Metabolic abnormalities and cardiovascular disease risk factors in adults with human immunodeficiency virus infection and lipodystrophy. Clin Infect Dis Off

15. Caballero AE. Endothelial dysfunction, inflammation, and insulin resistance: A focus on subjects at risk for type 2 diabetes. Curr Diab Rep 2004;4:237-46. https://doi.org/ 10.1007/s11892-004-0074-9.

16. Dooko CBA, Wit SD, Neuhaus J, Palfreeman A, Pepe R, Pankow JS, et al. Interleukin-6, high sensitivity C-reactive protein, and the development of type 2 diabetes among HIV-positive patients taking antiretroviral therapy. J Acquir Immune Defic Syndr 2014; 67:538-46.
17. Tawakol A, Lo J, Zanni M, Marmarelis E, Ihenachor $\mathrm{E}$, MacNabb $\mathrm{M}$, et al. Increased Arterial Inflammation Relates to High-Risk Coronary Plaque Morphology in HIV-Infected Patients. Jaids J Acquir Immune Defic Syndr 2014;66:164-71. https://doi.org/10.1097/ QAI.ooooooooooooo138.

18. Mendis S, Lindholm LH, Mancia G, Whitworth J, Alderman M, Lim S, et al. World Health Organization (WHO) and International Society of Hypertension (ISH) risk prediction charts: assessment of cardiovascular risk for prevention and control of cardiovascular disease in low and middle- income countries. J Hypertens 2007;25:1578-1582. https:// doi.org/10.1097/HJH.obo13e3282861fd3.

19. Recommandations ESC 2019: Dyslipidémies n.d. https://www.cardio-online.fr/ Actua lites/A-la-une/Recommandations-ESC-2019Dyslipidemia (accessed April 22, 2020).

20. Western Sub-Saharan Africa WHO cardiovascular disease risk charts pdf n.d.

21. Friis-Møller N, Weber R, Reiss P, Thiébaut R, Kirk O, Monforte A, et al. Cardiovascular disease risk factors in HIV patients association with antiretroviral therapy. Results from the D.A.D study. Aids 2003; 17:1179-93.

22. Unger Thomas, Borghi Claudio, Charchar Fadi, Khan Nadia A., Poulter Neil R., Prabhakaran Dorairaj, et al. 2020 International Society of Hypertension Global Hypertension Practice Guidelines. Hypertension 2020;75:1334-57. https://doi.org/ 10.1161/HYPERTENSIONAHA.120.15O26.

23. Anderson KM, Odell PM, Wilson PWF, Kannel WB. Cardiovascular disease risk profiles. Am Heart J 1991;121:293-8. https://doi.org/ 10.1016/ooo2-8703(91)9o861-B.

24. WHO updates Cardiovascular Risk Charts n.d. https://www.who.int/news-room/detail/o2o9-2019-who-updates-cardiovascular-risk-ch arts (accessed March 21, 2020).

25. Friis-Møller N, Thiébaut R, Reiss P, Weber R, Monforte AD, Wit SD, et al. Predicting the risk of cardiovascular disease in HIV-infected patients: the Data collection on Adverse 
Effects of Anti-HIV Drugs Study: Eur J Cardiovasc Prev Rehabil 2010. https:// doi.org/10.1097/HJR.obo13e328336a15o.

26. Landis JR, Koch GG. The Measurement of Observer Agreement for Categorical Data. Biometrics 1977;33:159-74. https://doi.org/ $10.2307 / 2529310$.

27. Muiru AN, Bibangambah P, Hemphill L, Sentongo R, Kim J-H, Triant VA, et al. Distribution and Performance of Cardiovascular Risk Scores in a Mixed Population of HIV-Infected and CommunityBased HIV-Uninfected Individuals in Uganda. J Acquir Immune Defic Syndr 1999 2018; 78:458-64. https://doi.org/10.1097/QAI. oooooooooooo1696.

28. Begovac J, Dragović G, Višković K, Kušić J, Perović Mihanović M, Lukas D, et al. Comparison of four international cardiovascular disease prediction models and the prevalence of eligibility for lipid lowering therapy in HIV infected patients on antiretroviral therapy. Croat Med J 2015;56:14-23. https://doi.org/10.3325/cmj. 2015.56.14.

29. Korten V, Gökengin D, Yildirmak T, Inkaya AC, Fincanci M, Caglayik DY, et al. Comparison of Risk Category Predictions of Framingham Risk Score (FRS), Atherosclerotic Cardiovascular Disease Risk Score (ASCVD), Systematic Coronary Risk Evaluation (SCORE) and Data Collection on Adverse Events of Anti-HIV Drugs (D:A:D) in HIV Infected Patients. Open Forum Infect Dis 2017;4:S215. https://doi.org/10.1093/ofid/ of $x 163.432$.

30. Edward AO, Oladayo AA, Omolola AS, Adetiloye AA, Adedayo PA. Prevalence of traditional cardiovascular risk factors and evaluation of cardiovascular risk using three risk equations in Nigerians living with human immunodeficiency virus. North Am J Med Sci 2013;5:680. https://doi.org/10.4103/19472714.123251.

31. Mashinya F, Alberts M, Van geertruyden J-P, Colebunders R. Assessment of cardiovascular risk factors in people with HIV infection treated with ART in rural South Africa: a cross sectional study. AIDS Res Ther 2015;12:42. https://doi.org/10.1186/s12981-015-0083-6.

32. Policarpo S, Rodrigues T, Moreira AC, Valadas E. Cardiovascular risk in HIV-infected individuals: A comparison of three risk prediction algorithms. Rev Port Cardiol Orgao Of Soc Port Cardiol Port J Cardiol Off J Port Soc Cardiol 2019;38:463-70. https://doi.org/ 10.1016/j.repc.2019.08.002.

33. Nery MW, Martelli CMT, Aparecida Silveira E, Sousa CA de, Falco M de O, Castro A de CO de, et al. Cardiovascular Risk Assessment: A Comparison of the Framingham, PROCAM, and D.A.D Equations in HIV-Infected Persons. Sci World J 2013. https://doi.org/ 10.1155/2013/969281.

34. Noumegni SR, Ama VJM, Assah FK, Bigna JJ, Nansseu JR, Kameni JAM, et al. Assessment of the agreement between the Framingham and D.A.D risk equations for estimating cardiovascular risk in adult Africans living with HIV infection: a cross-sectional study. Trop Dis Travel Med Vaccines 2017;3:12. https://doi.org/10.1186/s40794-O17-0055-z.

35. Yu SSK, Castillo DC, Courville AB, Sumner AE. The triglyceride paradox in people of African descent. Metab Syndr Relat Disord 2012;10:77-82. https://doi.org/10.1089/met. 2011.0108.

36. Sumner AE, Zhou J, Doumatey A, Imoisili OE, Amoah A, Acheampong $\mathrm{J}$, et al. Low HDL-Cholesterol with Normal Triglyceride Levels is the Most Common Lipid Pattern in West Africans and African Americans with Metabolic Syndrome: Implications for Cardiovascular Disease Prevention. CVD Prev Control 2010;5:75-80. https://doi.org/ 10.1016/j.cvdpc.2010.07.003.

37. Yayehd K, Damorou F, Akakpo R, Tcherou T, N'Da NW, Pessinaba S, et al. Prévalence de l'hypertension artérielle et description de ses facteurs de risque à Lomé (Togo) : résultats d'un dépistage réalisé dans la population générale en mai 2011. Ann Cardiol Angéiologie 2013;62:43-50. https://doi.org/10.1016/j. ancard.2012.09.006.

38. Djibril M, Baragou S, Pio M, Awide K, Damorou F, Redah D. Prevalence de 
l'hypertension arterielle dans la population adulte de Kara (ville secondaire du nord Togo). J Rech Sci L’Université Lomé 2011; 13:31-5.

39. Baragou S, Pio M, Atta P, Soussou BL. Prevalence de l'hypertension arterielle et des autres facteurs de risque cardiovasculaire en milieu professionnel Ouest Africain (Togo). J Rech Sci L'Université Lomé 2012; 14:105109-109.

40. Houehanou C, Amidou S, Preux P-M, Houinato D, Lacroix P. Hypertension artérielle (HTA) en Afrique subsaharienne. JMV-J Médecine Vasc 2018;43:87. https://doi.org/10.1016/j.jdmv.2017.12.032.

41. Wiernik Emmanuel, Pannier Bruno, Czernichow Sébastien, Nabi Hermann, Hanon Olivier, Simon Tabassome, et al. Occupational Status Moderates the Association Between Current Perceived Stress and High Blood Pressure. Hypertension 2013;61:571-7. https://doi.org/10.1161/HYPERTENSIONAH A.111.00302.

42. Larkin KT. Stress and hypertension: Examining the relation between psychological Stress and high blood pressure. Stress Hypertension Examining Relay Psychol Stress High Blood Press 2005:1-406.

43. Rayner BL, Spence JD. Hypertension in blacks: insights from Africa. J Hypertens 2017;35:234-9. https://doi.org/10.1097/ HJH.oooooooooooo1171.

44. Tu W, Pratt JH. A Consideration of Genetic Mechanisms Behind the Development of Hypertension in Blacks. Curr Hypertens Rep 2013;15:108-13. https://doi.org/10.1007/ s11906-013-0332-9.

45. Ab W, L G, A S. Whites excrete a water load more rapidly than blacks. Hypertens Dallas Tex 1979 2009;53:715-8. https://doi.org/ 10.1161/hypertensionaha.108.121665.

46. Chun T-Y, Bankir L, Eckert GJ, Bichet DG, Saha C, Zaidi S-A, et al. Ethnic differences in renal responses to furosemide. Hypertens Dallas Tex 1979 2008;52: 241-8. https:// doi.org/10.1161/HYPERTENSIONAHA.108.1 o9801.

47. Spence JD. Lessons from Africa: the importance of measuring plasma renin and aldosterone in resistant hypertension. Can $\mathrm{J}$ Cardiol 2012;28:254-7. https://doi.org/ 10. 1016/j.cjca.2011.11.o1o.

48. Calhoun DA, Nishizaka MK, Zaman MA, Thakkar RB, Weissmann P. Hyperaldosteronism among black and white subjects with resistant hypertension. Hypertens Dallas Tex 1979 2002;40:892-6. https://doi.org/ 10.1161/o1.hyp.ooooo40261.30455.b6.

49. Dhillon S, Sabin CA, Alagaratnam J, Bagkeris E, Post FA, Boffito M, et al. Level of agreement between frequently used cardiovascular risk calculators in people living with HIV. HIV Med 2019;20: 347-52. https://doi.org/ 10.1111/hiv.12731.

50. Pirš M, Jug B, Eržen B, Šabović M, Karner P, Poljak M, et al. Cardiovascular risk assessment in HIV-infected male patients: a comparison of Framingham, SCORE, PROCAM and D.A.D risk equations. Acta Dermatovenerol Alp Pannonica Adriat 2014; 23:43-7.https://doi.org/10.15570/actaapa.2 o14.11.

51. Serrano-Villar S, Estrada V, Gómez-Garre D, Ávila M, Fuentes-Ferrer M, San RJ, et al. Diagnosis of subclinical atherosclerosis in HIV-infected patients: higher accuracy of the D:A:D risk equation over Framingham and SCORE algorithms. Eur J Prev Cardiol 2014;21:739-48. https://doi.org/10.1177/ 2047487312452964. 
This page is intentionally left blank 